Products and Services In Practice is provided to readers using text and images from the manufacturer, supplier or distributor and does not imply endorsement by $B D J$ In Practice. Normal and prudent research should be exercised before purchase or use of any product mentioned.

Please send product and services news through to David Westgarth, $B D J$ In Practice via: David.Westgarth@bda.org

\section{Unique to your needs}

Clark Dental understands your unique needs and preferences when it comes to digital imaging and radiography. That's why the expert team offer a range of innovative solutions from MyRay, including the Hyperion X9 Pro.

As a compact 3-in-1 hybrid system for facilitating $2 \mathrm{D}$ and $3 \mathrm{D}$ examinations, the Hyperion X9 Pro offers CBCT, multipanoramic and cephalometric imaging programmes in SuperHD quality to ensure accurate diagnostics. This is further supported by fast Face To Face positioning for maximum patient and practitioner comfort.

With the Hyperion X9 Pro's wide scalability and modularity, you are also able to upgrade from a basic to an advanced version in a simple, costeffective way.

For more information call Clark Dental on 01268733 146, email info@clarkdental. co.uk or visit www.clarkdental.co.uk.

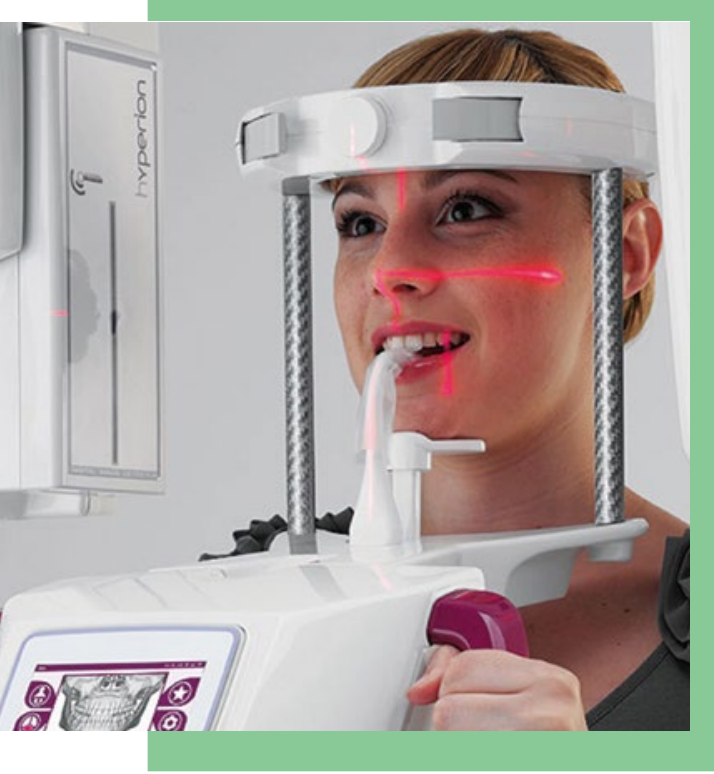

\title{
Implant education and referrals
}

Dental implants are increasingly sought after. If you lack the facilities or expertise to offer comprehensive implant treatment, why not refer implant surgery to the multi award-winning Ten Dental+Facial clinic, before the patient is returned to you for implant restoration?

You can learn to confidently and competently restore dental implants by joining Ten Dental+Facial's dedicated Implant Restoration Course (IRC).
Taught by highly experienced implant dentists, Drs Nikhil Sisodia and Martin Wanendeya, the IRC covers the theory and practice of restoring implants, enabling you to develop the knowledge and skills to manage both simple and complex cases.

Start meeting patient demand for dental implants by contacting Ten Dental+Facial and the IRC team via email on office@ tendental.com or call 02076227610 .

\section{Building confidence}

Following such a turbulent time in dentistry, it's important that any further changes you consider should be introduced gradually in order to build confidence among the team and your patients.

If you're thinking about upgrading technology or bringing in new products, or you just need some inspiration, the British Dental Conference and Dentistry Show is the place for you.
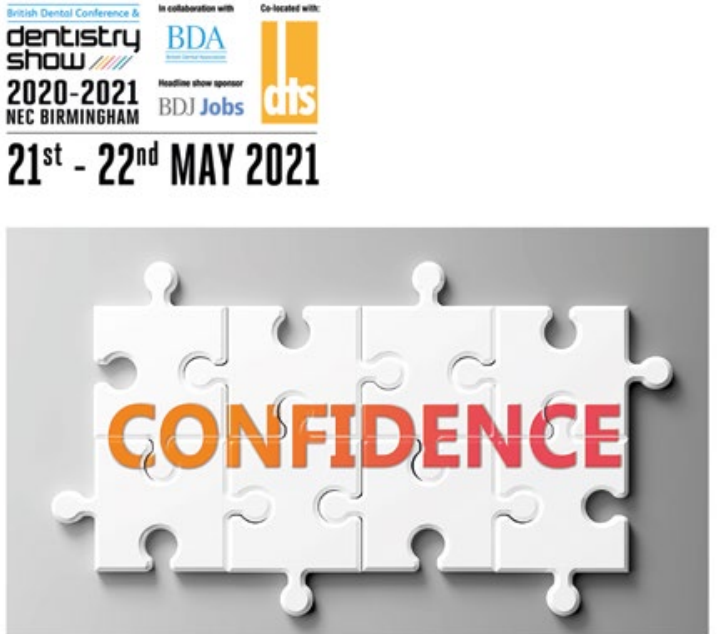

The next event will be held in May 2021, giving you plenty of time to settle into this 'new normal' before you start looking at the future. The educational programme include lectures, live demonstrations and workshops exploring the latest products, materials and technologies designed to enhance the quality and efficiency of care you deliver. There will also be an extensive trade floor with more than 400 dental manufacturers and suppliers to interact with.

When the time is right, we'll be here to help you take your business forwards.

The next British Dental Conference and Dentistry Show will be held on Friday 21 and Saturday 22 May 2021, Birmingham NEC, co-located with DTS. For more information visit www.thedentistryshow. co.uk, call 02073485270 or email dentistry@ closerstillmedia.com. 